\title{
The relationships between phenylthiocarbamide taste perception and smoking, work out habits and susceptibility to depression
}

\author{
Sevgi Daştan ${ }^{\text {** }}$, Yusuf Muhammed Durna ${ }^{2}$, Taner Daştan ${ }^{3}$ \\ ${ }^{1}$ Department of Zootechnical and Animal Nutrition, Faculty of Veterinary, Cumhuriyet University, 58140 Sivas, Turkey \\ ${ }^{2}$ Department of Otorhinolaryngology, Istanbul Training and Research Hospital, 34098 Istanbul, Turkey \\ ${ }^{3}$ Department of Chemistry, Institute of Applied Sciences, Bingol University, 12000 Bingol, Turkey
}

AR T I C L E IN F O

Article history:

Received 13 February 2015

Accepted 24 March 2015

Available online, ISSN: 2148-127X

Keywords.

PTC

Obesity

Taste genetics

Feeding behaviors

Taste perception

\begin{tabular}{l}
${ }^{*}$ Corresponding Author: \\
\hline E-mail: sdurna@ @umhuriyet.edu.tr
\end{tabular}

\begin{abstract}
A B S T R A C T
Phenylthiocarbamide (PTC) is known as phenylthiourea and it is an organic compound that has the phenyl ring. Ability to perceive the tastes of PTC chemical is related to the dominance of taste genes. There are a large number of population studies regarding the PTC taste perception and different personal characteristics or disease conditions. The purpose of this study is to reveal and compare the relation between the PTC taste perception and work-out habits, smoking, alcohol consumption and tendency to the depression of people. A total of 2500 adults were volunteered to be included in this study. PTC taste perception was measured by tasting with PTC solution $(10 \mathrm{mg} / \mathrm{L})$ filtered in a paper. It showed that tasters were significantly more frequent $(81.8 \%)$ than nontasters $(18.2 \%)$ in all population. And in some parameters analyzed in this study, there are significant differences. The taste genetics show up with environmental factors and create the sense of taste, which develops the feeding behaviors. The taste perception resulting from food and beverages diversifies by genetic and environmental effects and the nervous system interprets this perception. This study is enlightening in terms of presenting that the taste perception of people affects their lifestyles and lead them to start and either continue or discontinue some habits.
\end{abstract}

\section{Introduction}

Phenylthiocarbamide (PTC) is an organic compound having a phenyl ring which is also known as phenylthiourea (Padmavathi, 2013). Detecting the bitter taste of some substances such as Phenylthiocarbamide, Propylthiouracil or in other words, detecting the taste of $\mathrm{N}-\mathrm{C}=\mathrm{S}$ bond is a genetic feature showing bimodal distribution which is controlled by autosomal genes in accordance with Mendel Genetics (Kalmus and Hubbard, 1960; Saldhana and Becok, 1959; Stern, 1960; Kameswaran et al., 1974; Fischer et al., 1961; Bartoshuk, 2000; Blakeslee and Fox, 1932). These chemicals, depending on their genetic make-up, are distasteful for some people while they give the bitter taste to others. The people, who are very sensitive to these substances, are called supertasters and tasters who have homozygote dominant (TT) and heterozygote (Tt) genotypes respectively. The people who cannot get the taste of these substances are named as nontasters and they have homozygous recessive (tt) genotypes (Joiner and Perez, 2004; Fox, 1931; Bartoshuk et al., 1994; Duffy, 2004).

The allelic variation affecting the status of detecting the PTC/PROP tastes are located over chromosomes 5 and 7 in general (Duffy et al., 2004; Bufe, 2005; Tepper and Nurse, 1997). Thus, TAS2R38 polymorphisms that differ between individuals encode the functionally distinct receptor types, which directly affect the perception of bitter taste in the compounds containing $\mathrm{N}-\mathrm{C}=\mathrm{S}$. PTC/PROP detection tests are commonly performed on people, which give clues about the genetic structure and can be used as an endophenotypical marker (Padmavathi, 2013). Several studies were conducted in different geographies across the globe regarding the perception of PTC taste with different groups and communities (Guo and Reed, 2001). Considering the studies at the level of whole population, it has been observed that the rate of PTC nontasters varies between $1.4 \%$ and $66.7 \%$ in different groups and societies. According to these studies, the lowest rate for nontasters were obtained from a sample group of 70 people in North America; whereas the highest rate for nontasters were obtained from a sample group of 114 people in India (Guo and Reed, 2001). As a result of the population studies, it has been shown that the rate of PTC/PROP tasters varies in different societies and even in different groups of the societies. Anthropometric characters have been used to describe racial classifications for many years. However, the use of genetic characters is much more advantageous in terms of understanding the dynamics of human population genetics. Today, many polymorphic genetic markers are used for better understanding of human diversity 
(Padmavathi, 2013).

There are many studies conducted to obtain data related to PTC/PROP taste perceptions at population levels and to compare the disease cases and various personal characteristics regarding the perception of taste. It has been determined that there are differences between tasters and nontasters of these chemicals in terms of their personality styles and susceptibility to certain diseases like goiter, diabetes, peptidic ulcer, depression, alcoholism and schizophrenia (Dicarlo and Powers, 2001; Fischer et al., 1963; Kaplan et al., 1964; Henkin and Gillis, 1977; Harris et al., 1949; Kitchin et al., 1959; Memoria 1959; Brand 1963; Hollingsworth 1963; Compton et al., 2007; Moberg, 2005). Further studies are needed to investigate the relationship with different health problems. The aim of this study is investigating the relationship between the PTC taste perception and smoking and alcohol consumption, which affect the human life negatively and cause a variety of diseases, and the depression problem that we often encounter in today's living conditions. On the other hand, the correlation between the PTC taste perception and tendency of people to have regular work out activities were examined. Eventually, within this study, the connection between lifestyles of people depending on their habits and their PTC taste perceptions has been presented.

\section{Methodology}

\section{Establishment of the Working Group}

A total of 2500 adults (1510 female, 990 male) were volunteered to be included in this study from locals of Sivas and also the students of Sivas Cumhuriyet University. All participants were selected from healthy people, who don't have any upper respiratory infections, any treatment during the study and any problems related to taste/odor perception. Furthermore, the people with chronic sinusitis, chronic lung disease, diabetes, psychiatric disorders and taste disorders or dry mouth problems were excluded from the study. The study was initiated after receiving the approval of Cumhuriyet University Local Ethical Committee (decision number: 50/1552). The PTC perception, gender, eating habits, tea and coffee drinking habits, height, weight characteristics, age, information, regular exercise habits and body mass index (BMI) of the people were collected in a regular survey form and evaluated. The Body Mass Indexes were used, which are also used by the Ministry of Health, for BMI values of individuals.

\section{Preparation of PTC Solution}

In this study, the PTC solution was prepared by making some updates on the Harris and Kalmus (1949) method (Harris and Kalmus, 1949). PTC solution (10 $\mathrm{mg} / \mathrm{L}$ ) was absorbed into the filter paper (Zhao et al., 2003). On the other hand, since the responses of the people to PTC/PROP solutions may be relative, $\mathrm{NaCl}$ solution was used as the control solution; because the response of people to $\mathrm{NaCl}$ solution is always same. Therefore, tap water and $\mathrm{NaCl}$ solutions are used as control solutions in many studies to examine the taste perceptions. PTC and $\mathrm{NaCl}$ solutions were prepared in tap water and on the hot plate by dissolving the dust chemicals in the solution with continuous stirring. The solution was stored at $+4^{\circ} \mathrm{C}$ until it is used and kept in the room temperature before use (Tepper et al., 2001; Scott, 2004).

\section{Applying the Taste Test}

Some questions were asked to the participants such as whether they have smoked, eaten any food or drunk anything one hour prior to the taste test; if they have done one of these, the test was postponed for an hour. The methods used in the studies of Azevedo et al. (1965) and Tepper et al. (2001) were preferred while conducting experimental practices on people (Tepper et al., 2001; Azevedo et al., 1965). People were asked to rinse their mouth with tap water before starting the experiment and the same procedure was performed after each practice. After applying the PTC absorbed filter paper on the tongue for 30 seconds, their perceptions were asked if they have received any taste or any bitter taste. During the experimental practices, the individuals have stayed in a quiet environment without seeing each other. For those who did not mention any certain taste, the experiment was repeated in the next day. The individuals, who said that they did not taste anything and perceived the taste of $\mathrm{NaCl}$, were classified as PTC nontasters. Those who perceived the taste of PTC solution were classified as PTC taster individuals.

\section{Data Analysis}

SPSS ver 22.0 software packages were employed for the purpose of statistical analyzes of the data obtained. Chi-square analysis was performed between individual characteristics and perceptions of PTC.

\section{Results}

A total of 2500 volunteers participated in our study, in which we have investigated the relationship between the perception of PTC taste and the lifestyle habits of people depending on some habits. The age of participants ranged from 15 to 65 . PTC taste test was applied and the ratio of the individuals who can detect the PTC taste in our sample group has been identified according to the data obtained. According to these data, $81.8 \%$ of the people included in our study could detect the taste PTC, whereas the remaining $18.2 \%$ couldn't detect it. These rates are $83.4 \%$ and $16.6 \%$ in females and $79.4 \%$ and $20.6 \%$ in males, respectively (Table 1). Similar to the previous studies, it has been seen that the females are more sensitive in detecting the taste of PTC compared to the males (Duffy, 2004).

Considering the PTC perception levels of the individuals, who drink alcohol regularly and never drink, $83.3 \%$ of the individuals, who don't drink alcohol, can detect the taste of PTC, whereas this rate is $76.6 \%$ for those who drink alcohol regularly (Table 2). According to Pearson Chi-square analysis, the difference between two groups is important $(\mathrm{P} \leq 0.05)$. When individuals based on their smoking habits included in the study, the rate of 
those who can detect the taste of PTC is $83.1 \%$ among non-smokers, which is higher than the rate of smokers. According to the data we have obtained, the ratio of PTC tasters are higher in non-smokers and is significant $(\mathrm{P} \leq 0.05)$ (Table 3).

According to the individuals, whom we have conducted the study of the PCT taste perception with, based on their family members whether any first-degree relatives are diagnosed with depression, the data obtained were found to be very significant $(\mathrm{P} \leq 0.05)$. According to this, the rate of those, who have a first-degree relative diagnosed with depression, was $87.3 \%$ in terms of detecting the taste of PTC. Accordingly, it has been seen that the frequency of PTC tasters is higher it those, who have a first-degree relative diagnosed with depression (Table 4).

When we compared the PTC perception of the individuals by grouping them based on their regular work out activities; their PTC perception frequencies are close to each other. The rate of those who can detect the taste of PTC was $80.9 \%$ in the group with regular work out activities, whereas this rate was found as $82 \%$ in the other group who do not work out regularly. According to Pearson Chi-square test result, the difference between the groups $\mathrm{P}=0.591$ indicating that it is not significant $(\mathrm{P} \geq 0.05)$ (Table 5).

Table 1 Comparison of gender and PTC perception of individuals

\begin{tabular}{|c|c|c|c|c|c|c|}
\hline \multirow{2}{*}{\multicolumn{3}{|c|}{ Individuals }} & \multicolumn{2}{|c|}{ PTC } & \multirow{2}{*}{ Total } & \multirow{2}{*}{ P Value } \\
\hline & & & Tasted & Not Tasted & & \\
\hline \multirow{4}{*}{ Gender } & Femalo & Count & 1259 & 251 & 1510 & \multirow{6}{*}{$\mathrm{P}=0.012$} \\
\hline & Female & $\%$ within Gender & $83.4 \%$ & $16.6 \%$ & $100.0 \%$ & \\
\hline & Male & Count & 786 & 204 & 990 & \\
\hline & iviale & $\%$ within Gender & $79.4 \%$ & $20.6 \%$ & $100.0 \%$ & \\
\hline \multirow{2}{*}{\multicolumn{2}{|c|}{ Total }} & Count & 2045 & 455 & 2500 & \\
\hline & & $\%$ within Gender & $81.8 \%$ & $18.2 \%$ & $100.0 \%$ & \\
\hline
\end{tabular}

Table 2 Comparison of alcohol consumption and PTC perception of individuals

\begin{tabular}{|c|c|c|c|c|c|c|}
\hline \multirow{2}{*}{\multicolumn{3}{|c|}{ Individuals }} & \multicolumn{2}{|c|}{ PTC } & \multirow{2}{*}{ Total } & \multirow{2}{*}{ P Value } \\
\hline & & & Tasted & Not Tasted & & \\
\hline \multirow{2}{*}{ Alcohol } & Yes & $\begin{array}{l}\text { Count } \\
\% \text { within Alcohol }\end{array}$ & $\begin{array}{c}432 \\
76.6 \%\end{array}$ & $\begin{array}{c}132 \\
23.4 \%\end{array}$ & $\begin{array}{c}564 \\
100.0 \%\end{array}$ & \multirow{3}{*}{$\mathrm{P}=0.001$} \\
\hline & No & $\begin{array}{l}\text { Count } \\
\% \text { within Alcohol }\end{array}$ & $\begin{array}{c}1613 \\
83.3 \%\end{array}$ & $\begin{array}{c}323 \\
16.7 \%\end{array}$ & $\begin{array}{c}1936 \\
100.0 \%\end{array}$ & \\
\hline \multicolumn{2}{|l|}{ Total } & $\begin{array}{l}\text { Count } \\
\% \text { within Alcohol }\end{array}$ & $\begin{array}{c}2045 \\
81.8 \%\end{array}$ & $\begin{array}{c}455 \\
18.2 \% \\
\end{array}$ & $\begin{array}{c}2500 \\
100.0 \%\end{array}$ & \\
\hline
\end{tabular}

Table 3 Comparison of smoking habits and PTC perception of the individuals

\begin{tabular}{|c|c|c|c|c|c|c|}
\hline \multirow{2}{*}{\multicolumn{3}{|c|}{ Individuals }} & \multicolumn{2}{|c|}{ PTC } & \multirow{2}{*}{ Total } & \multirow{2}{*}{ P Value } \\
\hline & & & Tasted & Not tasted & & \\
\hline \multirow{2}{*}{ Smoking } & Yes & $\begin{array}{l}\text { Count } \\
\% \text { within Smoking }\end{array}$ & $\begin{array}{c}628 \\
79.0 \%\end{array}$ & $\begin{array}{c}167 \\
21.0 \%\end{array}$ & $\begin{array}{c}795 \\
100.0 \%\end{array}$ & \multirow{3}{*}{$\mathrm{P}=0.013$} \\
\hline & No & $\begin{array}{l}\text { Count } \\
\% \text { within Smoking }\end{array}$ & $\begin{array}{r}1417 \\
83.1 \% \\
\end{array}$ & $\begin{array}{c}288 \\
16.9 \% \\
\end{array}$ & $\begin{array}{c}1705 \\
100.0 \% \\
\end{array}$ & \\
\hline \multicolumn{2}{|l|}{ Total } & $\begin{array}{l}\text { Count } \\
\% \text { within Smoking }\end{array}$ & $\begin{array}{c}2045 \\
81.8 \%\end{array}$ & $\begin{array}{c}455 \\
18.2 \%\end{array}$ & $\begin{array}{c}2500 \\
100.0 \%\end{array}$ & \\
\hline
\end{tabular}

Table 4 Comparing those who have relatives diagnosed with depression and their PTC perceptions

\begin{tabular}{|c|c|c|c|c|c|c|}
\hline \multirow{2}{*}{\multicolumn{3}{|c|}{ Individuals }} & \multicolumn{2}{|c|}{ PTC } & \multirow{2}{*}{ Total } & \multirow{2}{*}{$\mathrm{P}$ Value } \\
\hline & & & Tasted & Not Tasted & & \\
\hline \multirow{2}{*}{$\begin{array}{l}\text { Depression } \\
\text { Disease Story }\end{array}$} & Yes & $\begin{array}{l}\text { Count } \\
\% \quad \text { within Use of } \\
\text { Depression Drugs }\end{array}$ & $\begin{array}{c}316 \\
87.3 \%\end{array}$ & $\begin{array}{c}46 \\
12.7 \%\end{array}$ & $\begin{array}{c}362 \\
100.0 \%\end{array}$ & \multirow{3}{*}{$\mathrm{P}=0.003$} \\
\hline & No & $\begin{array}{l}\text { Count } \\
\% \quad \text { within Use of } \\
\text { Depression Drugs }\end{array}$ & $\begin{array}{c}1729 \\
80.9 \%\end{array}$ & $\begin{array}{c}409 \\
19.1 \%\end{array}$ & $\begin{array}{c}2138 \\
100.0 \%\end{array}$ & \\
\hline \multicolumn{2}{|l|}{ Total } & $\begin{array}{l}\text { Count } \\
\% \quad \text { within Use of } \\
\text { Depression Drugs }\end{array}$ & $\begin{array}{c}2045 \\
81.8 \%\end{array}$ & $\begin{array}{c}455 \\
18.2 \%\end{array}$ & $\begin{array}{c}2500 \\
100.0 \%\end{array}$ & \\
\hline
\end{tabular}


Table 5 Comparing the PTC perception and regular work out activities of the individuals

\begin{tabular}{|c|c|c|c|c|c|c|}
\hline \multirow{2}{*}{\multicolumn{3}{|c|}{ Individuals }} & \multicolumn{2}{|c|}{ PTC } & \multirow{2}{*}{ Total } & \multirow{2}{*}{ P Value } \\
\hline & & & Tasted & Not Tasted & & \\
\hline \multirow{2}{*}{ Work Out } & Yes & $\begin{array}{l}\text { Count } \\
\% \text { within work out }\end{array}$ & $\begin{array}{c}369 \\
80.9 \%\end{array}$ & $\begin{array}{c}87 \\
19.1 \%\end{array}$ & $\begin{array}{c}456 \\
100.0 \%\end{array}$ & \multirow{3}{*}{$\mathrm{P}=0.591$} \\
\hline & No & $\begin{array}{l}\text { Count } \\
\% \text { within work out }\end{array}$ & $\begin{array}{c}1676 \\
82.0 \%\end{array}$ & $\begin{array}{c}368 \\
18.0 \% \\
\end{array}$ & $\begin{array}{c}2044 \\
100.0 \%\end{array}$ & \\
\hline \multicolumn{2}{|l|}{ Total } & $\begin{array}{l}\text { Count } \\
\% \text { within work out }\end{array}$ & $\begin{array}{c}2045 \\
81.8 \%\end{array}$ & $\begin{array}{c}455 \\
18.2 \% \\
\end{array}$ & $\begin{array}{c}2500 \\
100.0 \%\end{array}$ & \\
\hline
\end{tabular}

Table 6 PTC perception frequencies of individuals based on their ages

\begin{tabular}{|c|c|c|c|c|c|c|}
\hline \multirow{2}{*}{\multicolumn{3}{|c|}{ Individuals }} & \multicolumn{2}{|c|}{ PTC } & \multirow{2}{*}{ Total } & \multirow{2}{*}{$\mathrm{P}$ Value } \\
\hline & & & Tasted & Not tasted & & \\
\hline \multirow{6}{*}{ Age } & Young & Count & 1786 & 431 & 2217 & \multirow{8}{*}{$\mathrm{P}=0.001$} \\
\hline & Group 14-29 & $\%$ within Age Group & $80.6 \%$ & $19.4 \%$ & $100,0 \%$ & \\
\hline & Middle Age & Count & 196 & 13 & 209 & \\
\hline & Group 30-49 & $\%$ within Age Group & $93.8 \%$ & $6.2 \%$ & $100,0 \%$ & \\
\hline & Flders $50<$ & Count & 63 & 11 & 74 & \\
\hline & Elders $50<$ & $\%$ within Age Group & $85.1 \%$ & $14.9 \%$ & $100,0 \%$ & \\
\hline \multirow{2}{*}{\multicolumn{2}{|c|}{ Total }} & Count & 2045 & 455 & 2500 & \\
\hline & & $\%$ within Age Group & $81,8 \%$ & $18.2 \%$ & $100.0 \%$ & \\
\hline
\end{tabular}

The volunteers, who were included in the study to identify the PTC perception frequencies, were grouped under three classes according to their ages. As it can be seen on table 6, those who are between 14-29 years of age have formed the group of "Young", while the age group of 30-49 refers to "Middle age" people and those who are over the age of 50 were classified as "Elders". The PTC detection rates are $80.6 \%, 93.8 \%$ and $85.1 \%$ for these groups, respectively. According to Pearson chi-square analysis, these rates are very significant statically with the value of $\mathrm{P}=0.001$. Especially the PTC perception frequency of middle age group is clearly higher that the frequencies of other groups with a rate of $93.8 \%$. The lowest PTC perception frequency was seen in the "Young Age" group (Table 6).

\section{Discussion}

In this study, the correlation between detection of taste of PTC chemical and various habits of the individuals such as regular work out activities, use of alcohol and cigarette in their lifestyles and also depression stories of their members have been investigated. This is the most comprehensive research conducted in this area. The results are consistent with the studies of Saldanha (1962) regarding conducted in Portugal, Azevedo et al. (1965) conducted in Brazil and the results of Turkey mentioned in the study of Guo and Reed (2001) (Azevedo et al., 1965; Saldanha, 1962). According to the studies conducted so far, the distribution of PRC/PROP taste blindness (the ability and lack of detecting the taste of bitter chemicals) is as follows: $2.3-36.5 \%$ (Africa), 5.1$23 \%$ (China), 4.8-66.7\% (India), 2.0-27.5\% (Asia), 4.1$20.0 \%$ (Turkey), 49.3-50.0\% (Australia), 6.9-36.8\% (Europe) and $0-43.0 \%$ (USA), respectively (Guo and Reed, 2001; Tepper and Nurse, 1998; Saraswathi et al.,
2011; Tepper, 1998; Guo et al., 1998; Enoch et al., 2001). When the results compared with the results of a study mentioned in the book of Demirsoy (1998), which was conducted with 3643 people in Turkish community, it can be seen that the frequency of the taster individuals is higher in this study. According to the previous study, the percentage of the PTC taster individuals is $70.2 \%$, whereas this rate is $29.8 \%$ for nontasters (Demirsoy, 1998). There are differences between the values in different communities depending on ethnic differences, variations in the experimental group and homogenization of the participant profile. One of the crucial points in this study is not making a distinction between the tasters and supertasters as it was not done by Whittemore (1986, 1990). Those who can detect the taste of PTC were considered as a single group and the others who cannot detect the taste of PTC were considered as another group. It is not a good idea to classify the tasters as supertasters (homozygous TT) and tasters (Tt) since no specific research was conducted with individuals on the level of genes related to the perception of PTC.

In the comparison of the females and males in terms of PTC perceptions; the PTC perception frequencies of the females are considerably higher than the PTC perception frequencies of males. This result is consistent with a variety of research conducted before (Bartoshuk, 1994; Harris and Kalmus, 1949; Sisodia and Rao, 1968).

In this study, alcohol consumption was one another parameter that we have investigated its relationship with detecting the taste of PTC. According to the data, difference of PTC perception sensitivity between those who drink alcohol and don't drink alcohol is found statically significant $(\mathrm{P} \leq 0.05)$. According to the results of previous studies, the supertasters of PTC don't like drinking alcohol that much and it has been thought that 
they feel the oral burning and irritation of alcohol more severe than others (Bartoshuk et al., 1994). Therefore, in the population, it has been believed that the PTC tasters protect themselves against alcoholism. In contrast, it has been believed that since the nontasters have more insensitive against oral irritation and the bitter taste, they are more prone to alcoholism (Driscoll et al., 2006; Lanier et al., 2005; Prescott and Swain-Campbell, 2000). According to a study conducted with 3500 twin individuals in the United States, it has been reported that the taste heredity is controlled by direct and indirect mechanisms. Detecting the bitter taste of PTC/PROP is a phenotypic marker of a genetic variation on taste perception (Fox, 1931; Duffy, 2004; Harris and Kalmus, 1949). The previous studies have presented opposite results regarding the relationship between PTC/PROP perception and alcoholism.

Until now, various studies were conducted on the subject of a possible connection between PTC/PROP perceptions of individuals and their susceptibility to smoking. In general, it has been believed that the individuals who have a sensitivity of PTC perception don't consume substances such as cigarette and coffee that cause bitter taste and feeling of irritation in the mouth. It has been also presented that since the PTC nontasters cannot detect the bitter taste and dissatisfaction caused by smoking, they are in a tendency of smoking more cigarettes and they are at risk (Enoch et al., 2001). The results of this study support this information. In fact, the PTC perception frequency of nonsmokers is $83.1 \%$. This rate was found as $79 \%$ in smokers. The difference between these groups is statically significant $(\mathrm{P} \leq 0.05)$ and this can be considered as evidence showing that there is a relationship between the tendency to be addicted to nicotine and PTC perception. The use of cigarette seems to be growing rapidly in younger generations. The regular smoking habit begins almost before adolescence period. Therefore, protection methods must be provided by identifying the causes make these children addicted to nicotine.

One another subject, in which the relationship with PTC perception of the individual is investigated, is the existence of a relative diagnosed with depression. In our study, similar to the previous studies, the relationship between PTC perception and having a first-degree relative diagnosed with depression was investigated. The results that we have obtained are extremely interesting. The difference between these two groups in terms of PTC perception frequency is statically significant $(\mathrm{P} \leq 0.05)$. The results that we have obtained are consistent with the results of some studies conducted previously, in which the relationship between depression and PTC has been investigated (Dicarlo and Powers, 1998). However, there are also some other studies suggesting that there are a few cases supporting the relationship between the PTC taste buds and family-basis depression, which contradict with our study. For sure, these are propositions depending on the probability and not every single person, who has a family member diagnosed with depression, is a PTC taster. In addition, as a result of food preferences, PTC tasters can be vulnerable to major health problems such as cancer, depression and schizophrenia. In fact, there is evidence suggesting that PTC tasters are more anxious and nervous during personality formation compared to nontasters (Mascie-Taylor et al., 1983). Based on these personality results, Whittermore $(1986,1990)$ has stated that since PTC tasters have a tendency of being more anxious and nervous, they are more vulnerable to depression compared to nontasters (Whittemore, 1986, 1990). On the other hand, the gender and age variables should also be considered while evaluating the relationship between depression and PTC perception.

In this study, the relationship between regular work out habits of the individuals and their PTC perception has been investigated and no correlation has been identified between these two parameters. In fact, the PTC perception frequencies of both groups either work out or don't work out regularly, are close to each other and statically insignificant $(\mathrm{P} \geq 0.05)$.

Considering the method and sample group that we have created by optimizing in accordance with the studies in the literature; preparing a single PTC solution and conducting the taste test on people by absorbing the solution into a filter paper is sufficient in order to identify and compare the taste perception of individuals. It is an advantageous way in terms of providing the perceptions in a clear, quick, simple and affordable way (Tepper et al., 2001). In the study, we believe that we have stabilized the PTC perception by using the $\mathrm{NaCl}$ standard. In fact, similar methods were also used by some other studies in the literature (Dicarlo and Powers, 1998; Tepper et al., 2001; Bartoshuk et al. 1996; Prutkin et al., 2000; Prescott et al., 2004). Again, to ensure individuals' perception of taste, tap water is also used as well as $\mathrm{NaCl}$ solution to provide better comparisons.

In addition, it is also an important point that although the results of this study is consistent with the results of several studies conducted before, there are contradictions with some other studies (Guo and Reed, 2001). Due to the unreliable statistical factors, the results may be found as significant or insignificant by mistake. The small number of samples may also lead to varied statistics. Therefore, large-scale studies are needed due to the effect of random selection and population dynamics. Although this study has employed similar methodologies and statistics with many previous studies (Guo and Reed, 2001; Moberg et al., 2005; Moberg et al., 2007) it differs from others in terms of the methodology used and the higher number of the samples.

As a result, the taste genetics show up with environmental factors and create the sense of taste, which develops the feeding behaviours. Obesity may cause some types of cancer and creates the risk of cardiovascular disease. The taste perception resulting from food and beverages diversifies by genetic and environmental effects and the nervous system interprets this perception (Duffy, 2004). This study is enlightening in terms of presenting that the taste perception of people affects their lifestyles and lead them to start and either continue or discontinue some habits. 


\section{Acknowledgements}

This work is supported by Cumhuriyet University under the project of graduate research. In this study, I thank to Prof. Dr. Naci Değerli for his valuable contribution, Fazilet Yildiz for her help to the experimental work and Yavuz Yildir for his help to the statistical analysis. I also thank the Department of Biology for providing me the necessary facilities throughout the experiments.

\section{References}

Azevedo E, Krieger H, Mi MP, Morton NE. 1965. PTC taste sensitivity and endemic goller in Brazil. Am $\mathrm{J}$ of Hum Gen. Vol. 17:1.

Bartoshuk LM, Duffy VB, Miller IJ. 1994. PTC/PROP tasting: anatomy, psychophysics, and sex effects. Physiol \& Behav. 56 : 1165-1171.

Bartoshuk LM, Duffy VB, Reed D, Williams A. 1996. Supertasting, earaches and head injury: genetics and pathology alter our taste in worlds. Nuurosci biobehav Rev. 20: 9-87.

Bartoshuk LM. 2000. Psychophysical advances aid the study of genetic variation in taste. Appetite. 34:105.

Blakeslee AF, Fox AL. 1932. Our different taste worlds. J Hered. 23: 97-107.

Brand N. 1963. Taste sensitivity and endemic goitre in Israel. Arın. Hum. Genet. 26: 321-324.

Bufe B, Breslin PAS, Kuhn C, Reed DR, Tharp CD, Slack JP, Kim U, Drayna D, Meyerhof W. 2005. The molecular basis of individual differences in phenylthiocarbamide and propylthiouracil bitterness perception. Curr. Biol. 15: 423-327

Compton MT, Chien VH, Bollini AM, Walker EF. 2007. Lack of support for the inability to taste phenylthiocarbamide as an endophenotypic marker in patients with schizophrenia and their first- degree relatives. Schizophr Res. 95: 65 - 69 .

Demirsoy A. 1998. The Genetics and Evolution Book, 9.th Edition. pp.800.

Dicarlo ST, Powers AS. 1998. Propylthiouracil tasting as a possible genetic association marker for two types of alcoholism. Physiol \& Behav. 64: 147-152.

Driscoll KA, Perez M, Cukrowicz KC, Butler M, Joiner TE. 2006. Associations of phenylthiocarbamide tasting to alcohol problems and family history of alcoholism differ by gender. Psychiatry Research. 143: 21-27.

Duffy VB. 2004. Associations between oral sensation, dietary behaviors and risk of cardiovascular disease (CVD). Appetite. 43: 5-9.

Duffy VB, Peterson JM, Bartoshuk LM. 2004. Associations between taste genetics, oral sensation and alcohol intake. Physiol \& Behav. 82: 435-445

Enoch ME, Harris CR, Goldman D. 2001. Does a reduced sensitivity to bitter taste increase the risk of becoming nicotine addicted? Addictive Behaviours. 26: 399-404.

Fischer R, Griffin F, England S, Garn SM. 1961. Taste thresholds and food dislikes. Nature. 191: 1328.

Fischer R, Griffin F, Kaplan AR. 1963. Taste thresholds, cigarette smoking, and food dislikes, Medicina experimentalis, Int. J. Exp Clin Med. 9: 151-67.

Fox AL. 1931. Six in ten "tasteblind" to bitter chemical. Science News Letters. 92:115-120.

Guo SW, Shen FM, Zheng CJ, Wang Y. 1998. Treshold distributions of phenylth- iocarbamide (PTC) in the Chinese population. In: Murphy $\mathrm{C}$, ed. International Symposium on Olfaction and Taste XIX. Ann NY Acad Sci. 855: 810-812.

Guo SW, Reed DR. 2001. The genetics of phenylthiocarbamide perception. Ann. Hum. Biol. 28: 111-142.

Harris H, Kalmus H, Trotter WR. 1949. Taste sensitivity to phenylthiourea in goitre and diabetes. Lancet. 2: 1038-1039.
Harris H, Kalmus H. 1949. Chemical specificity in genetical differences of taste sensitivity. Ann. Eugen. 15: 32-45.

Henkin RI, Gillis WT. 1977. Divergent taste responsiveness to fruit of the tree Antidesma bunius, Nature. 265: 536-537.

Hollingsworth DR. 1963. Phenylthiourea taste testing in Hiroshima subjects with thyroid disease. Clin. Endocrinol. Metab. 23: 961963.

Joiner TE, Perez M. 2004. Phenylthiocarbamide tasting and family history of depression, revisited: low rates of depression in families of supertasters. Psychiatry Research. 126: 83-87.

Kalmus H, Hubbard SJ. 1960. Chemical senses in health and diseases. Springfield, C.C. Thomas. P. 95-101.

Kameswaran L, Gopalakrishnan S, Sukumar M. 1974. Phenylthiocarbamide and Naringin taste threshold in South Indian medical students. Indian J Pharmacol. 6: 134-140.

Kaplan AR, Glanville EV, Fischer R. 1964. Taste thresholds for bitterness and cigarette smoking. Nature. 202:1366.

Kitchin FD, Howels-Evan W, Clarke CA, Mcconnell RB, Sheppard PM. 1959. PTC taste response and thyroid disease. Brit. Med. J. 1: $1069-1074$.

Lanier SA, Hayes JE, Duffy VB. 2005. Sweet and bitter tastes of alcoholic beverages mediate alcohol intake in of -age undergraduatyes. Physiol \& Behav. 83: 821-831.

Mascie-Taylor CGN, McManus IC, MacLarnon AM, Lanigan PM. 1983. The association between phenylthiocarbamide (PTC) tasting ability and psychometric variables. Behav Gen. 13: 191196.

Moberg, PJ, Roalf DR, Balderston CC, Kanes SJ, Gur RE, Turetsky BI. 2005. Phenylthiocarbamide perception in patients with schizophrenia and first-degree family members. Am. J. Psychiatry. 162: 788-790.

Moberg PJ, McGue C, Kanes SJ, Roalf DR, Balderston CC, Gur RE, Kohler CG, Turetsky BI. 2007. Phenylthiocarbamide (PTC) perception in patients with schizophrenia and firstdegree family members: relationship to clinical symptomatology and psychophysical olfactory performance. Schizophr Res. 90: 221-228.

Padmavathi M. 2013. A Study on phenylthiocarbamide tasting in Bagatha Tribes in India. International Research Journal of Biological Sciences. 2: 33-36.

Prescott J. Swain-Campbell N. 2000. Responses to repeated oral irritation by capsaicin, cinnamaldehye and ethanol in PROP tasters and non-tasters. Chem Sense. 25: 239-246.

Prescott J, Soo J, Campbell H, Roberts C. 2004. Responses of PROP taster groups to variations in sensory qualities within foods and beverages. Physiol \&Behav. 82:459-469.

Prutkin J, Fisher EM, Etter L, Fast K, Gardner E, Lucchina LA, et al. 2000. Genetic variation and inferences about perceived taste intensity in mice and men. Physiol \& Behav. 69:161-73.

Saldhana PH, Becok N. 1959. Taste threshold for phenylthiourea among Askenazich Jews. Science. 129: 150-151.

Saldanha PH. 1962. Taste sensitivity to PTC among Brazilian Negroes and its bearing to the problem of White- Negro intermixture in Brazil. Human Biol. 34: 179-186.

Saraswathi YS, Najafi M, Vineeth VS, Kavitha P, Malini SS. 2011. Association of phenylthiocarbamide taste blindness trait with early onset of childhood obesity in Mysore. Journal of Paramedical Sciences. 2: 6-11.

Scott K. 2004. The sweet and the bitter of mammalian taste. Current Opinion in Neurobiology. 14: 423-427.

Sisodia P, Rao UR. 1968. Genetics andracial aspects of phenylthiocarbamide tasting ability in Indians. International symposium on "The role of Genetics today". September, 1968.

Stern C. 1960. Principles of human genetics. Freeman and Company, London. P. 167-169.

Tepper BJ. 1998. Genetics of perception 6-n-Propylthiouracil: a genetic marker for taste, with implications for food preference and dietary habits. Am J of Hum Genet. 63, 1271-1276.

Tepper BJ, Nurse RJ. 1997. Fat perception is related to PROP taster status. Physiol \& Behav. 61: 949-954. 
Tepper BJ, Nurse RJ. 1998. PROP taster status is related to fat perception and preference. Ann N Y Acad Sci. 855: 802 - 804.

Tepper BJ, Christensen CM, Cao J. 2001. Development of brief methods to classify individuals by PROP taster status. Physio \& Behav. 73: 571-577.
Whittemore PB. 1986. Phenylthiocarbamide (PTC) tasting and reported depression. Journal of Clinical Psychology. 42: 260 263.

Whittemore PB. 1990. Phenylthiocarbamide (PTC) tasting, genetics, and depression. Journal of Clinical Psychology. 46: 262-272.

Zhao GQ, Zhang Y, Hoon MA, Chandrashekar J, Erlenbach I, Ryba NJ, Zuker CS. 2003. The receptors form mamalian sweet and umami taste. Cell. 115: 255-266. 